\title{
Changes in Self-esteem in Participants Associated with Weight- loss and Maintenance of Commercial Weight Management Programme
}

\author{
James Stubbs $^{1 *}$, Sarah Hillier ${ }^{1}$, Carolyn Pallister $^{1}$, Amanda Avery $^{1}$, Aine McConnon ${ }^{2}$ and \\ Jacquie Lavin ${ }^{1}$ \\ ${ }^{1}$ Nutrition and Research Department, Slimming World, Derbyshire, UK \\ ${ }^{2}$ Department of Psychology, Food, Consumer Behavior and Health Research Centre, University of Surrey, Surrey UK
}

Received: February 19, 2015; Accepted: May 22, 2015; Published: June 15, 2015

*Corresponding author: James Stubbs, Nutrition and Research Department, Slimming World, Clover Nook Road, Alfreton, Derbyshire, DE55 4RF; Tel: 0177-3 54-6075; E-mail: james.stubbs@slimming-world.com

\begin{abstract}
Introduction and methods: This study examined associations between weight loss, its maintenance and self-esteem in 292 members of a commercial weight management organisation, Slimming World. Self-esteem was measured with the Rosenberg self-esteem questionnaire adapted to 5-point Likert scales. Associations between dimensions of self-esteem and weight change were examined by correlation and regression using the GENSTAT 5 statistical program.

Results: Mean (SD) weight on joining the CWMO was 89.0 (20.0) $\mathrm{kg}$; time taken to reach current weight was 16.3 (13.5) months. Mean (SD) weight change was -15.6 (11.4) kg and BMI change was -5.7 (4.0) (both $p<0.001$ ), maintained for 11.7 (12.8) months. Percent variance in weight change associated with each component of self-esteem is given in parentheses. All weight changes were negative. Participants reported a decrease in sense of failure (3.9\%) and an increase in self-respect (3.0\%) and self-pride (2.4\%). Self-satisfaction $(12.8 \%)$, feelings of self-achievement (10.6\%), positive attitudes towards themselves (9.9\%), sense of self-worth (10.6\%) and self-efficacy $(7.3 \%)$ all significantly increased in association with reaching and maintaining their current weight (all $p<0.001$ ). Multiple regression analysis showed that age, gender, height and start weight accounted for $35.4 \%$ of the variance in weight change. Self-esteem components of the model accounted for $50.4 \%$ of the variance in weight change.
\end{abstract}

Conclusion: Successful weight loss and maintenance was associated with significant reported improvements in self-esteem in members of a commercial weight management organisation.

Keywords: Weight maintenance; Self-esteem, Commercial weight management programme

\section{Introduction}

It is now well-documented that body weight is related to self-esteem, but the relationship is multifaceted, influenced by a number of mediators (factors contributing to the relationship between two conditions) and moderators (factors affecting the strength of the relationship between two conditions) and can be bi-directional: weight can influence self-esteem and vice versa [1]. High BMIs tend to be related to lower self-esteem in both adults and children as reported in many [2-6], but not in all studies [7-9]. The relationship between body weight and selfesteem is often moderated by culture, gender, age and ethnicity [1]. The relationship is mediated by a number of factors such as cultural norms [10], number of previous dieting attempts [11], intimate relationships [12], depression [13] and the degree of stigma that overweight people experience. Body weight is related to perceptions of body image and body dissatisfaction [7,14-16], whether those perceptions are directly related to weight or not [17]. In modern society, women tend to perceive themselves as more overweight and aspire to be leaner than they are, whereas men do not perceive themselves as overweight or obese [1]. This over-evaluation of body shape in women may well be influenced by self-criticism [3].

In their comprehensive meta-analysis review of the effects of weight loss on psychological well-being, Blaine et al. [2] compared the effects of bariatric surgery and drugs (a biomedical approach) with psychotherapeutic weight loss treatments (a psychosocial approach) in 117 studies. They found a tendency for these weight loss treatments to reduce depression and increase selfesteem. However, only treatments that produced actual weight loss increased self-esteem, while reductions in depression were independent of weight loss. Treatments using drugs/surgery were much better at reducing depression, but therapy-based treatments increased self-esteem much more than treatments using drugs/surgery [2]. These outcomes are interesting but do not address how more commonly used weight management programmes, such as community based lifestyle programmes, impact psychological outcomes such as self-esteem.

In recent years there is growing evidence of the effectiveness of commercial weight management programmes in the scientific community [18-23]. However, there are very few data on the impact of commercial weight management programmes on selfesteem among participants who have lost a significant amount 
of weight (i.e. $\geq 10 \%$ ). This survey assessed self-reported selfesteem and its association with a decrease in weight and BMI in members of a commercial weight management programme who had lost a significant amount of weight.

\section{Materials and Methods}

Two samples were recruited for this study. The first sample included subjects who were classified as Weight Loss Maintainers (WLM) attending a Commercial Weight Management Organisation (CWMO) and were contacted using the members' website. WLM were defined as members having reached and maintained their personally chosen target weight for at least 3 months. The invitation to complete the survey remained on the website for 1 month. A second sample included subjects who had participated in the Slimming World arm of the Diogenes study [24]. Both sample groups completed a short questionnaire and were offered the same incentive (entry into a prize draw to win $£ 100$ ). With the exception that the second sample had previously answered psychological and behavioural questions, as part of the Diogenes study, there was no difference in the interactions the researchers had with each sample. Both samples had continued to participate as members of the CWMO during the time of the survey. Subjects registered informed consent to taking part in the study by clicking a link to the questionnaire.

The questionnaire was divided into two sections, the first collected data on age, height, date of birth, duration of membership, time taken to reach current weight and time at current weight. Duration of membership, time taken to reach current weight and time at current weight data, were computed by assuming linearity and taking the mid-point of each time category, (i.e. 6 months or less as 3 months, 6 - 12 months as 9 months, 12 - 18 months as 15 months, 18 months - 2 years as 21 months, 2 - 3 years as 30 months, More than 3 years as 48 months). On average both samples had been long-term members (29.1 \pm 14.1 and $38.2 \pm 13.3$ months, respectively) and had lost a substantial amount of weight $(16.0 \pm 9.0$ and $15.3 \pm 13.7 \mathrm{~kg}$ respectively), which they had maintained for a mean (SD) of 11.1 (12.7) and 12.4 (13.0) months, respectively.

The second section of the questionnaire comprised of 5-point Likert scales asking questions about sources of help/support and reasons for trying to lose weight, behavioural strategies believed to have helped achieve weight loss, previous attempts at weight loss, motivational factors important to achieving and maintaining weight loss and retrospective, self-reported assessments of eating/activity habits and self-esteem (using the Rosenberg self-esteem scale [25]) before and after the subjects lost weight. Data were collected at one time point and so questions relating to "before weight loss" were retrospective. Data relating to self-esteem are reported here. Data relating to behavioural and motivation factors associated with WLM are published elsewhere [26]. This study was reviewed and approved by the University of Surrey Ethics Committee (approval: EC/2006/86/Psych).

Weight, age and height were self-reported by the participants themselves, for when they joined and at the time of questionnaire completion. The questionnaire was constructed and administered using Checkbox v4.4-Web Survey Software 2007, Prezza Technologies, Inc.

\section{Statistical Analysis}

Using height, start weight and end weight; the start and end BMI, weight and percent weight change were calculated. Associations between changes in self-esteem and weight change were examined by Pearson correlation coefficients. Associations between age, gender, height and start weight, self-esteem and weight change were analysed by fitting linear models and examining the significance of fitted terms in these models, through regression analysis. All analyses were performed using Microsoft Excel (2007) and the GENSTAT 5 statistical program (Genstat 5 Rothampstead Experimental Station, Harpenden, UK). Results are expressed as mean (SD), mean (SE) or as percentages where relevant.

\section{Results \\ Participants}

292 participants (277 women and 15 men) completed the survey and were included in the analysis. Mean (SD) joining weight (prior to weight loss) was 89.0 (20.0) kg; BMI was 32.6 (6.6) $\mathrm{kg} / \mathrm{m}^{2}$; height was 1.65 (0.07) $\mathrm{m}$; age was 47.0 (12.9) years; duration of membership was 29.1 (16.2) months. At the point of survey, weight and BMI (after weight loss) was 73.4 (16.3) kg and $26.9(5.6) \mathrm{kg} / \mathrm{m}^{2}$, respectively. Mean (SD) weight change was -15.6 (11.4) kg, BMI change was $-5.7(4.0) \mathrm{kg} / \mathrm{m}^{2}$, (all $p<0.001$ ), time to reach current weight was 16.3 (13.5) months and time at current weight, 11.7 (12.8) months.

\section{Changes in how participants felt about themselves before and after achieving a sustained weight loss}

Participants' responses to questions about their sense of self-worth, both before they joined the CWMO and after they had achieved their current weight are shown in Figure 1. All changes were significant at $p<0.001$. Percent variance in weight change associated with each variable is given in parentheses. Selfreported lack of self-respect (3.0\%), lack of self-pride (2.4\%) and sense of failure all decreased (3.9\%). Self-satisfaction (12.8\%), feelings of self-achievement (10.6\%), positive attitudes towards themselves (9.9\%), sense of self-worth (10.6) and self-efficacy (7.3\%) all significantly increased in association with reaching their current weight and maintaining it.

\section{Associations between changes in self-esteem and change in weight}

As all weight changes were negative (as all subjects were weight loss maintainers), a positive directional change in a component of the Rosenberg self-esteem questionnaire showing a negative correlation with weight, indicated that an increase in that variable was associated with weight loss. A negative directional change in a component of the Rosenberg self-esteem questionnaire showing a positive correlation with weight also indicated that the change in that behaviour was associated with weight loss. 
The direction of self-esteem and rank order of correlations between these outcomes and change in weight after the initial weight loss are reported in Table 1. Unifactorial regressions report percentage the variance in weight change that was associated with each component of self-esteem. All measures of self-esteem showed significant correlations with weight change $(p<0.001)$. Multiple regression models were computed for change in weight and BMI. Age, gender, height and start weight accounted for $35.4 \%$ of the variance in weight change, with selfesteem components of the model explaining $50.4 \%$ of the variance in weight change. By adding all components into a multipleregression analysis, the model shows that self-esteem explains a smaller percentage of the variance on aggregate compared to the sum of the variance explained by univariate regressions which indicates that there is some inter-dependence or overlap between some of the components i.e. some of the components explain part of the variance attributable to other components.

\section{Discussion}

\section{Changes in self-worth and self-esteem associated with weight loss and maintenance}

This study demonstrated that weight reduction $(-15.6 \mathrm{~kg}$ over 16.3 months), which was maintained (for 11.7 months), was associated with significant improvements in self-esteem. The self-reported changes in this present study are consistent with previous evidence that suggests obese women report low self-esteem, which improves following weight loss $[2,27]$. This study demonstrates that these effects are apparent in the context of a self-selected population of participants who had lost a significant amount of weight in a commercial weight management programme, although the results of this specific

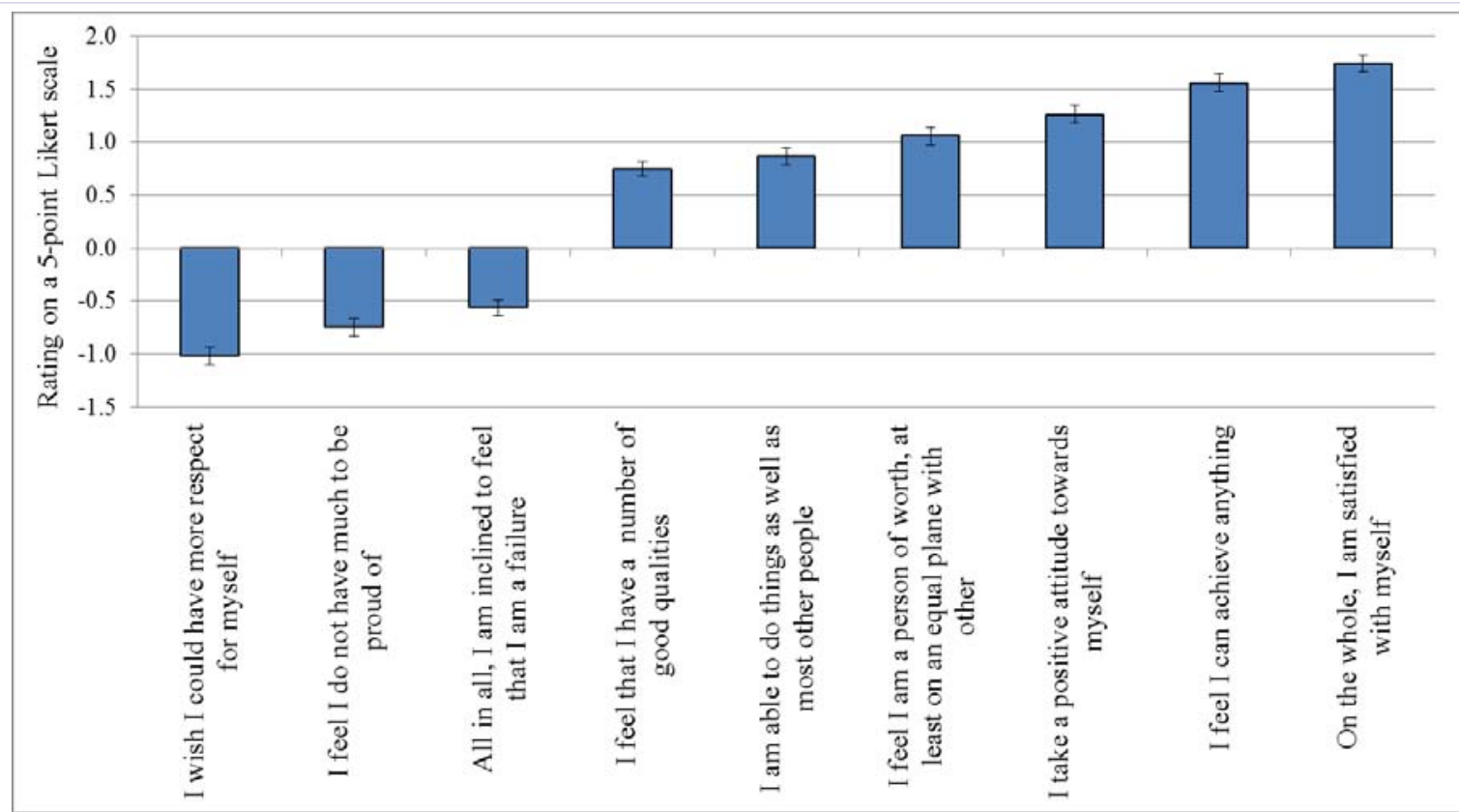

Figure 1: Mean (SE) difference in response to a 5-point Likert scale asking participants to describe how they felt about themselves before and after successful weight loss maintenance $(\mathrm{n}=292) .+$ denotes $p<0.001$.

Table 1: Correlations between changes in eating behaviours activity behaviours, self-worth and self-esteem and weight change ( $\mathrm{n}=292$ ).

\begin{tabular}{|c|c|c|c|}
\hline \multirow[t]{2}{*}{ Direction change } & \multirow{2}{*}{ Self-worth and esteem } & \multicolumn{2}{|c|}{ Weight Change } \\
\hline & & $\mathbf{r}$ & $\mathbf{p}$ \\
\hline+ & I felt I could achieve anything & -0.36 & $<0.01$ \\
\hline+ & On the whole, I am satisfied with myself & -0.35 & $<0.01$ \\
\hline+ & I feel I am a person of worth, at least on an equal plane with others & -0.34 & $<0.01$ \\
\hline+ & I took a positive attitude towards myself & -0.34 & $<0.01$ \\
\hline+ & I am able to do things as well as most other people & -0.33 & $<0.01$ \\
\hline+ & I feel that I have a number of good qualities & -0.28 & $<0.01$ \\
\hline- & All in all, I am inclined to feel that I am a failure & 0.24 & $<0.01$ \\
\hline- & I wish I could have more respect for myself & 0.24 & $<0.01$ \\
\hline- & I feel I do not have much to be proud of & 0.26 & $<0.01$ \\
\hline
\end{tabular}

Citation: Stubbs J, Hillier S, Pallister C, Avery A, McConnon A, et al. (2015) Changes in Self-esteem in Participants Associated with Weight-loss and Maintenance of Commercial Weight Management Programme. Obes Control Ther 2(1): 1-5. 


\author{
study are perhaps constrained to this context.
}

Many obese women have low self-esteem and lack confidence, both of which may improve following weight loss; they also feel discriminated against, and stigmatised by their weight $[2,27]$. Modern western society can be punitive and discriminating towards overweight people for many reasons [28-31]. These considerations suggest that to have maximum benefit to participants, weight management programmes should consider addressing both the behavioural (diet and physical activity) and emotional dimensions of weight control by helping people improve their self-criticism, self-esteem, self-worth, mentalwellbeing and coping-strategies through social support [1,32].

The results of the current study are however unable to disaggregate weight loss and weight loss maintenance. Improved self-esteem may therefore facilitate coping with lapses and so promote weight loss maintenance Turner et al [33]. Emphasise the importance of low self-esteem as a trigger for relapse [34]. A survey of 3394 men and women found women in particular, rated depression, stress, low self-esteem and the need to avoid social or sexual situations, as the more important reasons for weight gain compared to men and that women were also more likely to feel bad and regain weight as response to a relapse [35]. Similarly Byrne et al. [36] identified characteristics such as failure to achieve weight goals and dissatisfaction with weight achieved, tendency to evaluate worth in terms of weight and shape, a lack of vigilance with regards to weight control, dichotomous thinking and a tendency to use food to regulate mood are associated with weight regain but not maintenance [37]. Feelings of failure, stigma, self-criticism and shame may be key factors underlying relapse in people who have a tendency to do so and therefore should be investigated in future studies $[32,36]$.

\section{Limitations of the current study}

Many individuals who attend peer-support groups tend to be characterised by a common trait - they have a tendency to relapse [38-41]. Hence they seek the on-going support and stability that the safe environment of a peer-support, self-help group provides $[32,33]$. This suggests that there is both strength and a limitation to studies such as the current analyses. It is likely that this sample is a specific, self-selected sub-group, who represent individuals that successfully lose weight in a CWMO and maintain the loss, and may therefore not represent all individuals attempting to lose weight or the general population as a whole.

The current study is unable to determine if changes in selfesteem occurred before, during or as a consequence of weight loss. A weakness of the study lies in the implementation of retrospective questionnaires to compare the responses of the same subjects before and after their weight loss. However the use of this method has to be balanced against the difficulty of identifying successful weight loss maintainers prior to their weight loss.

In addition, the current study recruited predominantly female participants and as such future investigations should determine the differences between male and female responses to the psychological and behavioural aspects of weight loss and weight maintenance. Indeed depressions, degree of stigmatisation and self-criticism have close links with measures of self-esteem and were also not measured. Future research should therefore measure changes in these symptoms during both weight loss and weight maintenance.

\section{Conclusions}

Improvements in self-esteem were associated with long-term weight loss and maintenance in members of a CWMO. Future investigations should focus on developing the evidence base to determine the impact and relationship of weight loss through weight management programmes on the psychological and emotional aspects of well-being and weight control.

\section{References}

1. National Obesity Observatory, Obesity and mental health. 2011.

2. Blaine BE, Rodman J, Newman JM. Weight loss treatment and psychological well-being: a review and meta-analysis. J Health Psychol. 2007; 12(1):66-82.

3. Dunkley DM, Grilo CM. Self-criticism, low self-esteem, depressive symptoms, and over-evaluation of shape and weight in binge eating disorder patients. Behav Res Ther. 2007; 45(1):139-49.

4. Griffiths LJ, Parsons TJ, Hill AJ. Self-esteem and quality of life in obese children and adolescents: a systematic review. Int J Pediatr Obes. 2010; 5(4):282-304. doi: 10.3109/17477160903473697.

5. McAllister R, Caltabiano ML. Self-esteem, body-image and weight in noneating-disordered women. Psychol Rep. 1994; 75(3 Pt 1):133943.

6. Martin S, Housley K, McCoy H, Greenhouse P, Stigger F, Kenney MA, et al. Self-esteem of adolescent girls as related to weight. Percept Mot Skills. 1988; 67(3):879-84.

7. Pastore DR, Fisher M, Friedman SB. Abnormalities in weight status, eating attitudes, and eating behaviors among urban high school students: correlations with self-esteem and anxiety. J Adolesc Health. 1996; 18(5):312-9.

8. Rubinstein G. The big five and self-esteem among overweight dieting and non-dieting women. Eat Behav. 2006; 7(4):355-61.

9. Rumpel C, Harris TB. The influence of weight on adolescent selfesteem. J Psychosom Res. 1994; 38(6):547-56.

10. Davis C, Katzman MA. Chinese men and women in the United States and Hong Kong: body and self-esteem ratings as a prelude to dieting and exercise. Int J Eat Disord. 1998; 23(1):99-102.

11. Forster JL, Jeffery RW. Gender differences related to weight history, eating patterns, efficacy expectations, self-esteem, and weight loss among participants in a weight reduction program. Addict Behav. 1986; 11(2):141-7.

12.Geller J, Zaitsoff SL, Srikameswaran S. Beyond shape and weight: exploring the relationship between nonbody determinants of selfesteem and eating disorder symptoms in adolescent females. Int J Eat Disord. 2002; 32(3):344-51.

13. Kim O, Kim K. Body weight, self-esteem, and depression in Korean female. Adolescence. 2001; 36(142):315-22.

14. Mendelson BK, White DR, Mendleson MJ. Children's global self-esteem predicted by body-esteem but not by weight. Percept Mot Skills. 1995; $80(1): 97-8$. 
15. O'Dea JA. Self-concept, self-esteem and body weight in adolescent females: a three-year longitudinal study. J Health Psychol. 2006; 11(4):599-611.

16. van den Berg PA, Mond J, Eisenberg M, Ackard D, Neumark-Sztainer D. The link between body dissatisfaction and self-esteem in adolescents: similarities across gender, age, weight status, race/ethnicity, and socioeconomic status. J Adolesc Health. 2010; 47(3):290-6. doi: 10.1016/j.jadohealth.2010.02.004

17. Fox CL, Farrow CV. Global and physical self-esteem and body dissatisfaction as mediators of the relationship between weight status and being a victim of bullying. J Adolesc. 2009; 32(5):1287-301. doi: 10.1016/j.adolescence.2008.12.006.

18. Ahern AL, Olson AD, Aston LM, Jebb SA. Weight Watchers on prescription: an observational study of weight change among adults referred to Weight Watchers by the NHS. BMC Public Health. 2011; 11:434. doi: 10.1186/1471-2458-11-434.

19. Jebb SA, Ahern AL, Olson AD, Aston LM, Holzapfel C, Stoll J, et al Primary care referral to a commercial provider for weight loss treatment versus standard care: a randomised controlled trial. Lancet. 2011; 378(9801):1485-92. doi: 10.1016/S0140-6736(11)61344-5.

20. Lavin JH, Avery A, Whitehead SM, Rees E, Parsons J, Bagnall T, et al Feasibility and benefits of implementing a Slimming on Referral service in primary care using a commercial weight management partner. Public Health. 2006; 120(9):872-81.

21. Jolly K, Daley A, Adab P, Lewis A, Denley J, Beach J, et al. A randomised controlled trial to compare a range of commercial or primary care led weight reduction programmes with a minimal intervention control for weight loss in obesity: the lighten up trial. BMC Public Health. 2010; 10:439. doi: 10.1186/1471-2458-10-439.

22. Lloyd A, Khan R. Evaluation of healthy choices: a commercial weight loss programme commissioned by the NHS. Perspect Public Health. 2011; 131(4):177-83.

23. Stubbs RJ, Pallister C, Whybrow S, Avery A, Lavin J. Weight outcomes audit for 34,271 adults referred to a primary care/commercial weight management partnership scheme. Obes Facts. 2011; 4(2):113-20. doi: $10.1159 / 000327249$.

24. Larsen TM, Dalskov S, van Baak M, Jebb S, Kafatos A, Pfeiffer A, et al. The Diet, Obesity and Genes (Diogenes) Dietary Study in eight European countries - a comprehensive design for long-term intervention. Obes Rev. 2010; 11(1):76-91. doi: 10.1111/j.1467-789X.2009.00603.x.

25. Rosenberg M. Society and the adolescent self-image. Princeton, NJ: Princeton University Press; 1965.

26. Stubbs RJ, Brogelli D, Pallister C, Avery A, McConnon A, Lavin J. Behavioural and motivational factors associated with weight loss and maintenance in a commercial weight management programme. Open Obes J. 2012; 4:35-43. DOI: 10.2174/1876823701204010035

27. Hayden MJ, Dixon ME, Dixon JB, Playfair J, O’Brien PE. Perceived
Discrimination and Stigmatisation against Severely Obese Women: Age and Weight Loss Make a Difference. Obes Facts. 2010; 3(1):7-14. doi: $10.1159 / 000273206$.

28. Latner JD, O’Brien KS, Durso LE, Brinkman LA, MacDonald T. Weighing obesity stigma: the relative strength of different forms of bias. Int J Obes (Lond). 2008; 32(7):1145-52. doi: 10.1038/ijo.2008.53.

29. Puhl RM, Heuer CA. The stigma of obesity: a review and update. Obesity (Silver Spring). 2009; 17(5):941-64. doi: 10.1038/oby.2008.636.

30. Puhl RM, Heuer CA. Obesity stigma: important considerations for public health. Am J Public Health. 2010; 100(6):1019-28. doi: 10.2105/AJPH.2009.159491.

31. Schafer MH, Ferraro KF. The Stigma of Obesity: Does Perceived Weight Discrimination Affect Identity and Physical Health? Soc Psychol Q. 2011; 74(1):76-97. doi: 10.1177/0190272511398197.

32. Stubbs R.J. GC, Whybrow S., Gilbert P. The evolutionary inevitability of obesity in modern society: implications for behavioural solutions to weight control in the general population. In: Martinez MP, Robinson H., editor. Obesity and Weight Management: Challenges, Practices and Health Implications. Hauppauge, N.Y. In press.

33. Stubbs J, Whybrow S, Teixeira P, Blundell J, Lawton C, Westenhoefer $\mathrm{J}$, et al. Problems in identifying predictors and correlates of weight loss and maintenance: implications for weight control therapies based on behaviour change. Obes Rev. 2011; 12(9):688-708. doi: 10.1111/j.1467-789X.2011.00883.x.

34. Turner LW, Wang MQ, Westerfield RC. Preventing relapse in weight control: a discussion of cognitive and behavioral strategies. Psychol Rep. 1995; 77(2):651-6.

35. Cachelin FM, Striegel-Moore RH, Brownell KD. Beliefs about weight gain and attitudes toward relapse in a sample of women and men with obesity. Obes Res. 1998; 6(3):231-7.

36. Byrne S, Cooper Z, Fairburn C. Weight maintenance and relapse in obesity: a qualitative study. Int J Obes Relat Metab Disord. 2003; $27(8): 955-62$.

37. Gilbert P, Miles JM. Body Shame; Conceptualistion Research and Treatment. London: Routledge; 2014.

38. Brownell KD, Marlatt GA, Lichtenstein E, Wilson GT. Understanding and preventing relapse. Am Psychol. 1986; 41(7):765-82.

39. Moos R, Schaefer J, Andrassy J, Moos B. Outpatient mental health care, self-help groups, and patients' one-year treatment outcomes. J Clin Psychol. 2001; 57(3):273-87.

40. Moos RH. Active ingredients of substance use-focused self-help groups. Addiction. 2008; 103(3):387-96. doi: 10.1111/j.13600443.2007.02111.x.

41. Munn-Giddings C, McVicar A. Self-help groups as mutual support: what do carers value? Health Soc Care Community. 2007; 15(1):26-34. 